\title{
Development of the Adolescent Cancer Suffering Scale
}

\author{
Christelle Khadra RN MSc ${ }^{1,2}$, Sylvie Le May RN PhD ${ }^{1,2}$, Isabelle Tremblay PhD ${ }^{3}$, \\ France Dupuis RN PhD ${ }^{1,2}$, Chantal Cara PhD RN ${ }^{1}$, Geneviève Mercier RN MSc ${ }^{4}$, \\ Marie France Vachon $\mathrm{RN} \mathrm{MSc}^{4}$, Jacinthe Lachance Fiola $\mathrm{PhD}^{1,2}$
}

\begin{abstract}
C Khadra, S Le May, I Tremblay, et al. Development of the Adolescent Cancer Suffering Scale. Pain Res Manag 2015;20(4):213-219.
\end{abstract}

BACKGROUND: While mortality due to pediatric cancer has decreased, suffering has increased due to complex and lengthy treatments. Cancer in adolescence has repercussions on personal and physical development. Although suffering can impede recovery, there is no validated scale in French or English to measure suffering in adolescents with cancer.

OBJECTIVE: To develop an objective scale to measure suffering in adolescents with cancer.

METHODS: A methodological design for instrument development was used. Following a MEDLINE search, semistructured interviews were conducted with adolescents 12 to 19 years of age who had undergone four to six weeks of cancer treatment, and with a multidisciplinary cohort of health care professionals. Adolescents with advanced terminal cancer or cognitive impairment were excluded. Enrollment proceeded from the hematology-oncology department/clinic in Montreal, Quebec, from December 2011 to March 2012. Content validity was assessed by five health care professionals and four adolescents with cancer.

RESULTS: Interviews with 19 adolescents and 16 health care professionals identified six realms of suffering: physical, psychological, spiritual, social, cognitive and global. Through iterative feedback, the Adolescent Cancer Suffering Scale (ACSS) was developed, comprising 41 questions on a four-point Likert scale and one open-ended question. Content validity was 0.98 , and inter-rater agreement among professionals was $88 \%$ for relevance and $86 \%$ for clarity. Adolescents considered the scale to be representative of their suffering.

CONCLUSIONS: The ACSS is the first questionnaire to measure suffering in adolescents with cancer. In future research, the questionnaire should be validated extensively and interventions developed. Once validated, the ACSS will contribute to promote a holistic approach to health with appropriate intervention or referral.

Key Words: Adolescents; Cancer; Pediatric cancer; Questionnaire; Scale development; Suffering

$\mathrm{C}$ ancer is the leading disease-related cause of death in Canadians one to 19 years of age (1). Survival rates have improved over recent years (2), largely as a result of newer and more complex cancer treatments. Nonetheless, these therapeutic modalities have also increased patient suffering (3).

A cancer diagnosis in adolescence has major implications on personal and physical development because this is a pivotal period of growth and maturation (4). Cancer and anticancer therapies are associated with pain and fatigue $(5,6)$; they also affect body image $(4,7)$, selfesteem (8), relationships and peer acceptance (9). Furthermore, the adolescent patient and his or her peer group are suddenly faced with addressing premature mortality, whether one's own or that of a peer.

\section{La mise au point d'une échelle de mesure de la souffrance chez les adolescents ayant le cancer}

HISTORIQUE : La mortalité causée par le cancer pédiatrique a diminué, mais la souffrance a augmenté en raison des traitements longs et complexes. Le cancer à l'adolescence a des répercussions sur le développement personnel et physique. Même si la souffrance peut nuire au rétablissement, il n'y a pas d'échelle validée en français ou en anglais pour mesurer la souffrance chez les adolescents atteints du cancer.

OBJECTIF : Mettre au point une échelle objective pour mesurer la souffrance subjective des adolescents atteints du cancer.

MÉTHODOLOGIE : Les chercheurs ont utilisé un concept méthodologique pour créer un outil. Après une recherche dans MEDLINE, ils ont réalisé des entrevues semi-structurées auprès d'adolescents de 12 à 19 ans qui avaient subi un traitement oncologique de quatre à six semaines, ainsi qu'auprès d'une cohorte multidisciplinaire de professionnels de la santé. Les adolescents atteints d'un cancer terminal avancé ou ayant une atteinte cognitive ont été exclus. Les participants avaient fréquenté un département et clinique d'hématologie-oncologie de Montréal, au Québec, entre décembre 2011 et mars 2012. Cinq professionnels de la santé et quatre adolescents ayant le cancer ont évalué la validité du contenu.

RÉSULTATS : Les entrevues auprès de 19 adolescents et 16 professionnels de la santé ont permis de circonscrire six champs de souffrance : physique, psychologique, spirituel, social, cognitif et global. Selon des commentaires itératifs, les chercheurs ont créé l'échelle de mesure de la souffrance chez les adolescents ayant le cancer (ÉMSAC), composée de 41 questions sur une échelle de Likert en quatre points et d'une question ouverte. La validité du contenu était de 0,98 et la concordance interévaluateurs entre professionnels, de $88 \%$ sur le plan de la pertinence et de $86 \%$ sur celui de la clarté. Les adolescents trouvaient que l'échelle était représentative de leur souffrance.

CONCLUSIONS : L'ÉMSAC est le premier questionnaire à mesurer la souffrance chez les adolescents atteints du cancer. Dans de futures recherches, il faudra procéder à une validation approfondie du questionnaire et mettre au point des interventions. Une fois validée, l'ÉMSAC contribuera à promouvoir une approche globale de la santé, assortie d'interventions ou d'orientations pertinentes.

Various studies have attempted to describe suffering in adolescents. A qualitative study on adolescents with cancer revealed an "indescribable" and "embodied" suffering (10). Participants in the study were unable to pinpoint which symptoms caused them the most suffering because all were difficult to bear; every aspect of the disease engendering suffering in some way (10). Suffering was also associated with loss (loss of health, loss of control) $(11,12)$. It was continually changing in quality and occurred at all stages of the disease, from early symptoms to diagnosis to remission and/or palliative care $(12,13)$. A diagnosis of cancer was perceived by many patients as a death sentence $(12,14)$.

Suffering is defined as a subjective, complex experience associated with deep emotional distress $(15,16)$, a response to a threat or injury to

${ }^{1}$ Faculty of Nursing, University of Montreal; ${ }^{2}$ Centre hospitalier universitaire Sainte-Justine Research Center; ${ }^{3}$ Department of Psychology;

${ }^{4}$ Department of Hematology/Oncology, Centre hospitalier universitaire Sainte-Justine, Montreal, Quebec

Correspondence: Dr Sylvie Le May, Faculty of Nursing, University of Montreal, PO Box 6128, Succursale Centre-Ville, Montreal,

Quebec H3C 3J7. Telephone 514-343-6384, fax 450-621-3960, e-mail sylvie.lemay@umontreal.ca 


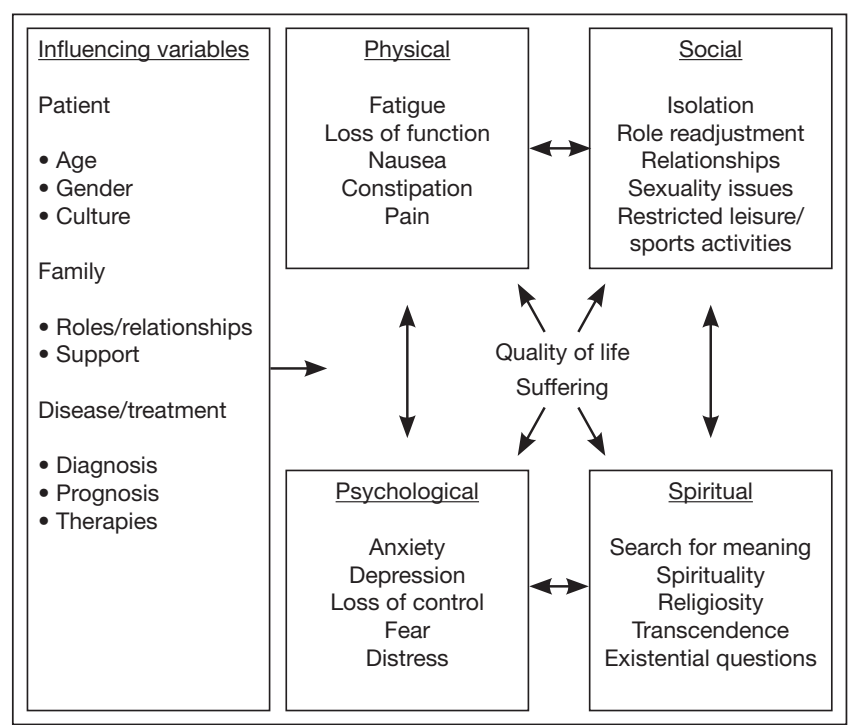

Figure 1) Conceptual model used in the design of the Adolescent Cancer Suffering Scale, adapted from Ferrell's Quality of Life Model Applied to Cancer Survivors (22)

various aspects of personhood (15) that encompasses physical, psychological, social and spiritual dimensions (3). If not well managed, suffering may lead to short- and long-term consequences. Suffering threatens personal integrity $(15,17)$ and alters one's sense of reality, attributing negative connotations to lifetime events (16). It also creates a sense of injustice and depreciation (18). Affecting psychological, social and somatic well-being (18), suffering can impede recovery or worsen prognosis. For all these reasons, alleviation of suffering needs to be incorporated into health care.

However, a thorough review of the literature failed to identify a validated scale in French or in English or, indeed, any scale applicable to the North American adolescent context. The Cancer Patient's Suffering Scale was developed by Kaneko in 1999 and validated using 242 adult patients hospitalized in Tokyo (19). It is a 40-item scale divided into four subscales of suffering: physical, psychological, social and existential. Although psychometric properties are good (19), the Cancer Patient's Suffering Scale is not appropriate for use in North American adolescents. First, culture has been shown to play a crucial role in the perception and experience of pain $(12,15,20)$, and the cultural context faced by adolescents in North America is very different from that in Japan. Importantly, the scale was validated in an adult population, whereas the characteristics of adolescence make this a very distinct age group. Finally, the scale is available only in Japanese. Similarly, Kang's scale assessing suffering in cancer was developed and validated in Korea in 1999, using 160 cancer patients and 185 healthy individuals (21). The final version yielded 38 items with good psychometric properties, and is only available in Korean.

The aim of the present study was, therefore, to develop a scale to measure suffering in North American adolescents diagnosed with cancer. It will allow nurses and clinicians to recognize and document suffering in their patients and be able to intervene efficiently or refer for appropriate consult.

\section{METHODS}

\section{Conceptual model and design}

Due to the paucity of literature with regard to questionnaires investigating suffering, the conceptual model was based on the components of the quality of life model in cancer survivors described by Ferrell (22). Ferrell defined quality of life from a multidimensional perspective including four domains of patient well-being: physical, psychological, social and spiritual. Although distinct, each domain is able to influence the others $(22,23)$. This model is particularly relevant to
TABLE 1

Open-ended questions to elicit item generation during semistructured interviews with participants

1. How would you describe your/your patients' overall experience with cancer?

2. How did cancer affect each of the following aspects of your/your patients' life: a) physical, b) psychological, c) spiritual and d) social well-being?

3. How would you describe suffering and its manifestations?

4. Which treatment(s) caused or causes you/your patients the most suffering?

5. Within the entire cancer spectrum, what caused or causes you/your patients the most suffering?

6. Do you have any additional comments you would like to add to describe suffering in your/your patients' lives as teenagers with cancer?

suffering because it recognizes its multidimensional aspect and because suffering could often derive from a poor quality of life. Figure 1 presents the model adapted for the present study. Age was included as a crucial determinant in adolescents. A diagnosis of cancer during this period of transition exacerbates personality issues, with treatmentinduced changes in physical appearance and an altered self-image $(4,8,9)$. The characteristics of each domain were also adopted to fit the concept of suffering. For scale development, the methodological design described by Streiner and Norman (24) was used, as well as steps proposed by Le May et al (25) for instrument development.

\section{Participants}

All participants, including patients and health care professionals, were recruited from the Hematology/Oncology Department of a pediatric teaching hospital and its associated outpatient clinic in Montreal, Quebec. The study was approved by the institutional review board. Participants $\geq 18$ years of age provided written informed consent; minor participants gave assent along with written consent from their parents/legal guardians.

A convenience sampling method was used for patient recruitment. Enrollment occurred between December 2011 and March 2012. Patients were eligible if they were 12 to 19 years of age at the time of enrollment; had been diagnosed with cancer; had previously completed four to six weeks of cancer therapy (to have experienced treatment and related side effects); were aware of their illness, treatment plan and side effects; and could speak, read and understand French.

Patients were excluded if they: had advanced terminal cancer; had cognitive impairment according to medical records including autism, dyslexia or mental disability; or were in remission for $>1$ year (to avoid memory loss bias).

Health care professionals were recruited through purposive sampling to maximize information (26). To better understand the concept of suffering from different perspectives, caregivers and researchers from various specialties (nursing, medicine, clinical psychology, experimental psychology, spiritual care, art therapy and music therapy) were recruited. Clinicians working at the pain clinic and in palliative care were also included. There were no other criteria such as age requirement or minimum years of experience.

Data collection

To obtain data regarding patient suffering over the course of the disease, one author (CK) conducted individual interviews with participants. For patients, the interviews were held in a private office at the clinic or in the patient's room; for health care professionals, they were held in their office. The interviews were semistructured, based on a list of open-ended questions (Table 1) that were compiled from the literature on suffering and adolescent experiences with cancer as well as from the authors' clinical expertise. Each question was adapted 
to either the patient or health care professional context. Audiotaped interviews were transcribed by a professional secretary to facilitate analysis.

\section{Item generation}

A MEDLINE search was performed to identify key components to include in a questionnaire on suffering, using the following key words: suffering, adolescents, cancer, questionnaire, scale and instrument. Once the participants had been interviewed, the Corbin and Strauss method of immersion, coding, categorization and grouping was used to analyze the content of the interviews and communications (27). Each transcript was read several times to increase sensitivity for identifying cues and meanings (immersion). The authors examined the data and contextual references, made constant comparisons and searched for differing meanings of words (27). Line-by-line analysis was performed to assign appropriate codes to meaningful units, using MAXQDA 10 Plus (VERBI GmbH, Germany), a qualitative data analysis software.

Codes were then counted for repetition and identification of categories (categorization). The purpose of this quantification was to determine the most recurrent codes that should be addressed in the scale (grouping) as well as the percentage of items (questions) that should be assigned to each category. Two of the coauthors were experts in qualitative content analysis (FD) and pediatric oncology (MFV, FD). Based on their judgment, the authors agreed on the codes to be included.

\section{Item reduction}

Reduction of items was performed by the principal investigator and two coauthors, by selecting the most relevant items according to the criteria proposed by Streiner and Norman (24) such as interpretability, reading level, ambiguity and length of items. To enhance the credibility of this preliminary version of the scale, the process was repeated by an external reviewer, who was a physician with experience in oncology and research; this was followed by peer debriefing for comparison.

\section{Content validity}

Content validity was assessed by submitting the reduced pool of items to a panel of five health care professionals of various specialties (from the group already interviewed) and four new patients (using the same inclusion/exclusion criteria). These numbers were chosen based on recommendations in Rubio et al (28) to assure expertise and diversity of knowledge. Each health care professional was asked to indicate, on the response form, the relevance of each item on a Likert scale ranging from 1 to 4 , as per Rubio et al (28): 1, not relevant; 2, needs major revision to be relevant; 3 , needs minor revision; and 4 , relevant. Item clarity was similarly tested. In addition, the patient group was asked to assess whether they understood each item and whether they could provide a response. Each of the two parts of the question was rated on a Likert scale ranging from 1 to 4: 1, very easy; 2, easy; 3, difficult; and 4 , very difficult. If necessary, patients were asked to rewrite the item in their own words. This process helped to identify items that were irrelevant or unclear. As a final iteration, the same panel of patients and health care professionals was asked to review all the items on the list and to modify, add or delete any items still considered to be irrelevant or unclear.

\section{Data analysis}

Content validity responses were analyzed based on the method described by Rubio et al (28). Inter-rater agreement (IRA) was calculated for relevance and clarity of each item by dichotomizing the fourpoint scale, combining choices 1 and 2 together and 3 and 4 together. To determine the IRA of the entire scale, the number of items considered to be $100 \%$ relevant or clear (score of 4 on the Likert scale) was divided by the total number of items (28). The content validity index (CVI) was calculated for each item to indicate the overall rating of its relevance by health care professionals (28). The number of health care professionals who rated an item with a score of 3 or 4 was divided by the total number of health care professionals on the panel.
TABLE 2

Patient characteristics ( $n=19)$

\begin{tabular}{|c|c|}
\hline Characteristic & n (\%) \\
\hline \multicolumn{2}{|l|}{$\overline{\text { Sex }}$} \\
\hline Male & $13(68.4)$ \\
\hline Female & $6(31.6)$ \\
\hline \multicolumn{2}{|l|}{ Age, years } \\
\hline 12 & $1(5.3)$ \\
\hline 13 & $1(5.3)$ \\
\hline 14 & $2(10.5)$ \\
\hline 15 & $1(5.3)$ \\
\hline 16 & $7(36.7)$ \\
\hline 17 & $4(21.1)$ \\
\hline 18 & $3(15.8)$ \\
\hline \multicolumn{2}{|l|}{ Number of siblings } \\
\hline 0 & $3(15.7)$ \\
\hline 1 & $8(42.1)$ \\
\hline 2 & $6(31.6)$ \\
\hline 3 & $1(5.3)$ \\
\hline 4 & $1(5.3)$ \\
\hline \multicolumn{2}{|l|}{ Background } \\
\hline Canadian & $16(84.2)$ \\
\hline Other & $3(15.8)$ \\
\hline \multicolumn{2}{|l|}{ Cancer type } \\
\hline Leukemia & $12(63.1)$ \\
\hline Lymphoma & $2(10.4)$ \\
\hline Adrenocortical carcinoma & $1(5.3)$ \\
\hline Liver cancer & $1(5.3)$ \\
\hline Brain germinoma & $1(5.3)$ \\
\hline Medulloblastoma & $1(5.3)$ \\
\hline Osteosarcoma & $1(5.3)$ \\
\hline \multicolumn{2}{|l|}{ Treatment received } \\
\hline Chemotherapy & $19(100)$ \\
\hline Radiotherapy & $7(36.8)$ \\
\hline Surgery & $7(36.8)$ \\
\hline Bone marrow transplant & $3(15.8)$ \\
\hline
\end{tabular}

The average CVI for all items combined represents the CVI of the scale. Rubio et al (28) suggested a cut-off of 0.80 for CVI or IRA per item to determine relevance and clarity for inclusion. Accordingly, items below that level were removed from the scale.

\section{Participant characteristics}

\section{RESULTS}

Of the 23 patients approached, four declined because they were very tired and did not wish to be interviewed, yielding a response rate of $83 \%$ (19 of 23). All 16 health care professionals approached agreed to participate. The sample of participants for item generation thus comprised 19 adolescent patients with cancer and 16 health care professionals.

The patient group consisted of 13 boys $(68.4 \%)$ and six girls. The mean age was 15.9 years (median 16 years, range 12 to 18 years) (Table 2). Most patients were Canadian (84.2\%) and almost twothirds had a diagnosis of leukemia. All had previously undergone chemotherapy. All of the health care professionals had at least five years' experience with the population of interest. The content validation panel was composed of five clinicians from the health care professionals group and four patients (two boys [13 and 15 years of age] and two girls [14 and 16 years of age]; mean age 14.5 years).

\section{Item generation}

Patient interviews for item generation lasted $11 \mathrm{~min}$ to $30 \mathrm{~min}$ each (mean $18 \mathrm{~min}$ ); health care professional interviews lasted $11 \mathrm{~min}$ to 


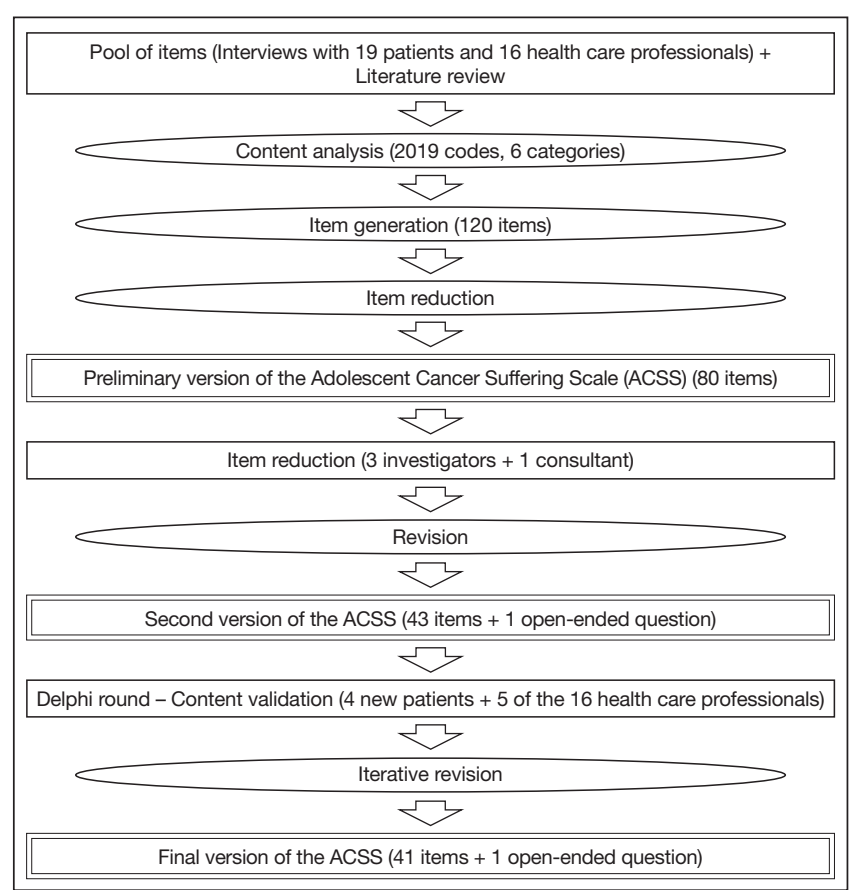

Figure 2) Flow chart showing the step-by-step development of the Adolescent Cancer Suffering Scale

56 min each (mean $26 \mathrm{~min}$ ). The various steps of development of the Adolescent Cancer Suffering Scale (ACSS) are summarized in Figure 2.

Six themes emerged during the content analysis of the transcripts. The main themes and subthemes are presented in Table 3. In total, 2019 meaningful units were coded. Any subthemes that appeared with $<10$ codes within a particular theme were grouped together into the subtheme 'Other'. Codes were identified if they related to the literature review themes and the four domains of the Ferrell Model (physical, psychological, social and spiritual). Two further themes emerged: cognitive suffering and global suffering. The codes were further classified into subcodes, which were included in the most meaningful category.

Most codes $(n=740$ [36.7\%]) were associated with physical suffering, followed by 532 (26.3\%) codes associated with psychological suffering. The extent to which adolescents with cancer had a tendency to protect their parents' feelings was noticeable ( 51 codes, accounting for $12 \%$ of the social suffering domain), with social suffering having 423 codes (21\%). Although spiritual suffering was not very recurrent during the interviews $(n=111$ [5.5\%] codes), the quest for meaning and the sense of injustice were noteworthy. The new domain of cognitive suffering ( $n=59$ codes [2.9\%]) reflected the angst and frustration felt by many patients when experiencing delays in their studies compared with their peers, and/or learning difficulties after completing their treatment. Fatigue was cited as one of the causes of learning setbacks, as were difficulty concentrating and memorizing new information. Finally, 154 (7.6\%) codes referred to global suffering, such as the in vivo code (label taken from the wording used by participants) "it's difficult". Signs associated with global suffering included isolation, unwillingness to talk or share feelings, exaggerated positive affect and engaging in high-risk behaviours.

\section{Item reduction}

The 2019 codes were first grouped into 120 items, which were further refined, after a Delphi round, to 80 items to form the preliminary version of the scale. After examining the preliminary version for interpretability, reading level, ambiguity and length, the three investigators and the external reviewer then reduced the items to approximately one-half ( $n=43$ items) for the second version of the scale.
TABLE 3

Main themes and subthemes emerging from patient and professional interviews

\begin{tabular}{|c|c|}
\hline Types of suffering & $\begin{array}{l}\text { Number of codes } \\
(n=2019)\end{array}$ \\
\hline Physical & $740(36.7)$ \\
\hline $\begin{array}{l}\text { Alteration of body image (alopecia, weight change, } \\
\text { self-image) }\end{array}$ & $208(28.1)$ \\
\hline $\begin{array}{l}\text { Therapies (chemotherapy, radiotherapy, surgery, } \\
\text { bone marrow) }\end{array}$ & $112(15.1)$ \\
\hline Pain & $100(13.5)$ \\
\hline $\begin{array}{l}\text { Changes in mobility and functioning (movement } \\
\text { restriction, lack of independence) }\end{array}$ & $94(12.7)$ \\
\hline Gastric difficulties (nausea, vomiting, loss of appetite) & $60(8.2)$ \\
\hline Fatigue & $41(5.5)$ \\
\hline Other & $125(16.9)$ \\
\hline Psychological & $532(26.3)$ \\
\hline $\begin{array}{l}\text { Fear (of the unknown, of the future, of death, anxiety, } \\
\text { stress, loss of hope) }\end{array}$ & $141(26.5)$ \\
\hline Mood swings (irritability, anger, sadness) & $131(24.6)$ \\
\hline $\begin{array}{l}\text { Defence mechanisms (denial, difficulty accepting, } \\
\text { trying to forget) }\end{array}$ & $79(14.8)$ \\
\hline Frustration and discouragement & $30(5.6)$ \\
\hline Other & $151(28.5)$ \\
\hline Social & $423(21.0)$ \\
\hline $\begin{array}{l}\text { Changed relationships with peers (diminished school } \\
\text { rank/status, peer judgement, diminishing peer group, } \\
\text { marginalization, loneliness) }\end{array}$ & $133(31.4)$ \\
\hline $\begin{array}{l}\text { Changes in habits and activities of daily life } \\
\text { (hospitalizations, doctors' appointments, school } \\
\text { absenteeism/dropped courses, sports/activities) }\end{array}$ & $128(30.3)$ \\
\hline $\begin{array}{l}\text { Family concerns (protective attitude toward parents, } \\
\text { need for constant support, sense of burden) }\end{array}$ & $51(12.1)$ \\
\hline $\begin{array}{l}\text { Romantic relationships (difficulty initiating and/or } \\
\text { maintaining) }\end{array}$ & $37(8.7)$ \\
\hline Other & $74(17.5)$ \\
\hline Spiritual & $111(5.5)$ \\
\hline Existential (quest for meaning, sense of injustice) & $71(64.0)$ \\
\hline $\begin{array}{l}\text { Religious (questioning faith, religious and transcendental } \\
\text { meanings) }\end{array}$ & $35(31.5)$ \\
\hline Other & $5(4.5)$ \\
\hline Cognitive & $59(2.9)$ \\
\hline Delays/setbacks in academic studies & $23(39.0)$ \\
\hline Learning and reintegration difficulties & $12(20.4)$ \\
\hline Cognitive problems (attention, alertness, memory) & $11(18.6)$ \\
\hline Other & $13(22.0)$ \\
\hline Global & $154(7.6)$ \\
\hline Signs of suffering (isolation, silences, distraction) & 109 (70.8) \\
\hline Difficulty adjusting (“It's difficult”) & $20(13.0)$ \\
\hline Other & $25(16.2)$ \\
\hline
\end{tabular}

Data presented as n (\%)

\section{Content validity}

IRA: The IRA was calculated for the answers provided by the five health care professionals (content experts) and four adolescent patients (lay experts) regarding relevance and clarity. Based on the percentage of items rated as $100 \%$ relevant, the IRA for relevance among health care professionals was $88 \%$, versus only $49 \%$ among patients, for an overall IRA of $40 \%$. Similarly, the IRA for clarity was $86 \%$ and $74 \%$, respectively, for an overall $63 \%$.

CVI: The CVI represented feedback by the five health care professionals regarding the content of each item and of the scale as a whole. Only five items had a CVI of 0.80 ; the remainder had a CVI of 1 . The CVI for the overall scale was 0.98 . 
Wording assessment: The group of four adolescent patients considered $36(84 \%)$ of the items to be very easy to understand and $32(74 \%)$ very easy to answer (on a Likert scale ranging from 1 , very easy, to 4 , very difficult). Some of the items rated as more difficult to answer were the same as those rated difficult to understand, such as, "I can't use my body as I'd like to" (free-style translation). Others needed to be more specific, such as, "I find it hard to cope with treatments" (free-style translation). Overall, however, the lay expert group rated the scale as representative of their experience with cancer and anticancer therapies.

\section{The ACSS}

Based on the feedback from content and lay experts, the final version of the ACSS was revised to 41 items and one open-ended question that allowed the adolescents to express any issues related to their suffering that were not included in the scale (Appendix 1). The ACSS is a self-administered questionnaire that takes approximately $5 \mathrm{~min}$ to $10 \mathrm{~min}$ to complete. Responses are on a four-point Likert scale: 1 , never; 2 , occasionally; 3 , most of the time; and 4, always; with an additional choice of N/A (not applicable). The total score is the sum of responses to each item. The greater the score, the greater the suffering. The ACSS questionnaire also includes several reversed items to avoid the bias of acquiescence, or the tendency to check similar responses regardless of import (24). Therefore, the scores of items 14,15 and 32 should be inverted before the total score is computed. Negatively worded items, such as 'not' or 'never', were avoided for clarity (24).

\section{DISCUSSION}

Inspired by the work of Cassell (29) and Kahn and Steeves (30), research in the past few decades has increasingly focused on suffering as a distinct element from physical pain. To our knowledge, we have developed the first North American or European scale to measure suffering in adolescents with cancer. A rigorous process of instrument development has yielded the ACSS, which incorporates six domains: physical, psychological, social, spiritual, cognitive and global suffering. It was designed to reflect the items most frequently mentioned in the literature and in interviews with the two populations of interest: adolescents with cancer and cancer care professionals. Combined with a nurse's intimate knowledge of the patient, the ACSS can be included in the patient's chart to facilitate handover at nursing shift changes or used during follow-up for extended treatments and/or recurrences specific to cancer. These considerations should make the ACSS a valuable tool in the assessment of suffering, enabling accurate referral and intervention.

Although the main elements of the model described by Ferrell (22) are common to most of the studies investigating suffering, the subthemes that emerged during the content analysis of the interviews were categorized somewhat differently. For instance, we assigned some of the subthemes, such as 'lack of control', 'concerns about death' and 'uncertain future', to the psychological domain; in their study on patients with advanced cancer, Wilson et al (31) had considered these to be spiritual (existentialist). Furthermore, the ACSS recognizes two new domains - cognitive suffering and global suffering - which were not included in any of the previous literature. Cognitive suffering may be more specific to adolescents than adults because academic standing determines rank among peers for age grouping, achievements and even career choices, whereas these considerations are mostly inconsequential in the adult population. 'Global suffering' encompassed more than the sum of the parts; we found specific manifestations of suffering that could not be attributed to any of the other domains but rather revealed a general overall experience affecting the adolescent.
The CVI is one of the most rigorous methods to determine content validity (24). Based on feedback from our health care professionals, the CVI for the ACSS was 0.98. Adolescents tended to rate the relevance of each item subjectively, based on whether they personally experienced it. Based on the percentage of items they rated as $100 \%$ relevant, the IRA for the overall scale was only $49 \%$ for adolescents, compared with $88 \%$ for health care professionals. The IRA for clarity was $74 \%$ and $86 \%$, respectively.

The four adolescents from the lay experts group agreed that the ACSS described their experience well. This was considered to be extremely positive because the intent of the authors was to find items related to all stages of adolescence, knowing that concerns differed depending on age, cancer diagnosis and therapeutic management. According to Schrijvers and Meijnders' classification (32), young adolescents with cancer (10 to 14 years of age) were mostly concerned with physical appearance, mobility and disruption of normal relations with peers, while mid-teenagers (15 to 17 years of age) focused more on loss of autonomy and social marginalization (32). The main challenge was to find items that pertained to all stages of adolescence. The ACSS appears to have attained that goal.

\section{Limitations}

Suffering assumes various meanings predicated on the surrounding culture (20). The present study was conducted in a large tertiary care institution of a cosmopolitan Canadian city. It was difficult to enrol a homogenous group of participants of the same ethnic background because the setting from which the sample was recruited for the development of the scale provides cancer care services to a multiethnic population, where its clientele comes from the greater Montreal area and across all of Quebec. Montreal is known to have a large proportion of multiethnic habitants. Second, the development of the scale did not include family members. Due to their intimate experience with siblings with cancer, it would have been instructive to obtain their opinions during the interviews before item development.

\section{CONCLUSION}

The holistic approach to health care stresses the prevention and reduction of patient suffering. We have developed the ACSS to enable health care professionals to better measure suffering and, thus, to intervene more efficiently. This scale should also prove useful to oncology researchers. Future studies should focus on extensive validation of the measure with a larger sample to determine its other psychometric properties, as well as on developing interventions according to the different levels or areas of suffering reflected in the scale.

ACKNOWLEDGEMENTS: The authors thank the patients and their families, as well as all the registered nurses, physicians and psychologists of the Hematology/Oncology Department for their cooperation and contribution to the study. The authors would also like to acknowledge the support from Danielle Buch, medical writer/editor at the Applied Clinical Research Unit of the CHU Sainte-Justine Research Center, for her rigor and judicious comments on the review of this manuscript and for substantive editing thereof. Finally, the authors would like to acknowledge the support received from Pain In Child Health, a strategic research training initiative of the Canadian Institutes of Health Research, where some of the co-authors were trainees (CK, JLF) and one is a coinvestigator (SLM).

DISCLOSURES: The authors have no conflicts of interest to declare.

FUNDING: This study was supported by grants from the Quebec Interuniversity Nursing Intervention Research Group (GRIISIQ), CHU Sainte-Justine Foundation, CHU Sainte-Justine Research Center, and the Foundation of Stars. 


\section{Khadra et al}

\section{APPENDIX 1}

\section{Échelle de Souffrance des Adolescents ayant le Cancer (ESAC): Version finale des items}

Nous te prions de cocher (X) une seule réponse, de (1) Jamais à (4) Tout le temps, pour chacun des commentaires ci-dessous en pensant uniquement à la période allant depuis le début de ta maladie jusqu'à présent. Si l'énoncé ne s'applique pas à ta condition, STP coche la case "Non applicable ».

De temps en La plupart du Tout le temps Non applicable Jamais (1) temps (2) temps (3)

1 Je trouve la chimiothérapie difficile à subir/recevoir

2 Je trouve les traitements difficiles à subir (radiothérapie, transfusions, prélèvements, etc.)

3 Je me sens fatigué(e)

4 J'ai de la difficulté à dormir

5 Mon appétit a changé

$6 \quad$ J'ai des nausées

7 Le changement de mon poids à cause de la maladie et des traitements me préoccupe

8 Je me trouve moins beau/belle

9 Je ressens de la douleur physique

10 Je trouve la douleur physique difficile à supporter

11 J'ai de la difficulté à marcher seul (e)

12 Les contraintes reliées à ma maladie me dérangent (ports de masque, lunette à oxygène, orthèses, etc.)

13 Je trouve difficiles les changements à mon alimentation (habitudes alimentaires)

14 Je suis capable d'utiliser mon corps comme je le souhaiterais

15 De façon générale, je me sens en forme

16 Je me sens en colère face à ma maladie

17 Je me sens découragé (e)

18 J'ai de la difficulté à accepter que je sois malade

19 Je suis dérangé (e) d'avoir peu de contrôle sur les évènements liés à ma maladie (traitements, pronostic, évolution, etc.)

20 Mon avenir me préoccupe

21 J'ai peur de mourir

22 J'évite de penser à ma maladie

23 Je suis facilement irritable ou en colère

24 Je suis triste

25 J'ai peur de faire de la peine à ma famille

26 J'ai besoin d'être entouré(e) par ma famille

27 J'ai de la difficulté à établir ou à maintenir des liens amoureux à cause de ma maladie

28 C'est difficile de participer à des activités avec mes amis

29 Je me sens jugé (e) par mon entourage

30 C'est difficile d'arrêter de pratiquer les sports et/ou les activités que j'aimais

31 Je me sens seul (e)

32 J'ai des camarades à qui je peux parler de mes préoccupations

33 C'est difficile d'être à l'hôpital (hospitalisé ou à la clinique externe pour recevoir les traitements)

34 C'est difficile de ne plus aller à l'école (études, amis, routine, etc.)

35 C'est difficile de communiquer mes sentiments au personnel médical et infirmier

36 J'ai de la difficulté à me concentrer sur mes études ou mes travaux

37 Je pense que c'est injuste d'avoir le cancer à mon âge

38 Je cherche un sens à ma maladie

39 II est difficile pour moi de parler de ce qui me dérange ou de communiquer mes sentiments

40 J'évite de voir du monde quand je ne me sens pas bien

$41 \quad$ Je trouve que le traitement est long

As-tu d'autres commentaires à ajouter concernant ta souffrance ou la souffrance en général ? 


\section{REFERENCES}

1. Canadian Childhood Cancer Surveillance and Control Program. Diagnosis and initial treatment of cancer in Canadian adolescents 15 to 19 years, 1995 to 2000. Ottawa: Health Canada; 2004.

2. Canadian Cancer Society. Canadian Cancer Statistics 2012. Toronto, Canada 2012. < www.cancer.ca/ /media/cancer.ca/CW/ cancer\%20information/cancer\%20101/Canadian\%20cancer\%20 statistics/Canadian-Cancer-Statistics-2012-.-English.pdf> (Accessed December 2013).

3. Fochtman D. The concept of suffering in children and adolescents with cancer. J Pediatr Oncol Nurs 2006;23:92-102.

4. Abrams AN, Hazen EP, Penson RT. Psychosocial issues in adolescents with cancer. Cancer Treat Rev 2007;33:622-30.

5. Ameringer S. Barriers to pain management among adolescents with cancer. Pain Manag Nurs 2010;11:224-33.

6. Erickson J. Fatigue in adolescents with cancer: A review of the literature. Clin J Oncol Nurs 2004;8:139-45.

7. Larouche S, Chin-Peuckert L. Changes in body image experienced by adolescents with cancer. J Pediatr Oncol Nurs 2006;23:200-9.

8. Fan SY, Eiser C. Body image of children and adolescents with cancer: A systematic review. Body Image 2009;6:247-56.

9. Williamson H, Harcourt D, Halliwell E, Frith H, Wallace M. Adolescents' and parents' experience of managing the psychosocial impact of appearance change during cancer treatment. J Pediatr Oncol Nurs 2010;27:168-75.

10. Woodgate RL. Feeling states: A new approach to understanding how children and adolescents with cancer experience symptoms. Cancer Nurs 2008;31:229-38.

11. Morse J. Towards a praxis theory of suffering. Adv Nurs Sci 2001;24:47-59.

12. Ferrell B, Coyle N. The Nature of Suffering and the Goals of Nursing. New York: Oxford University, 2008.

13. Kuuppelomäki M, Lauri S. Cancer patients' reported experiences of suffering. Cancer Nurs 1998;21:364-9.

14. Kellehear A. On dying and human suffering. Palliat Med 2009;23:388-97.

15. Cassell EJ. The Nature of Suffering and the Goals of Medicine. New York: Oxford University Press; 2004.
16. Rodger B, Cowles K. A conceptual foundation for human suffering in nursing care and research. J Adv Nurs 1997;25:1048-53.

17. Chapman CR, Gavrin J. Suffering: The contributions of persistent pain. Lancet 1999;353:2233-7.

18. Rodriguez A. La souffrance. Effondrement et refondation des valeurs. Ethique Santé 2004;64-9.

19. Kaneko M. Development of a cancer patients' suffering scale. Journal of St. Luke's Society for Nursing Research 1999;3:25-32.

20. Barton-Burke M, Barreto RC, Archibald LIS. Suffering as a multicultural cancer experience. Semin Oncol Nurs 2008;24:229-36.

21. Kang, KA. Development of a tool to measure suffering in patients with cancer. J Korean Acad Nurs 1999;29:1365-78.

22. Ferrell B. The quality of lives: 1,525 voices of cancer. Oncol Nurs Forum 1996;23:907-16.

23. Ferrell BR, Dow K. Quality of life among long-term cancer survivors. Oncology 1997;11:565-8.

24. Streiner DL, Norman GR. Health Measurement Scales: A Practical Guide to Their Development and Use. New York: Oxford, 2008.

25. Le May S, Dupuis G, Taillefer M, Dubé S, Hardy J-F. Clinimetric scale to measure surgeons' satisfaction with anesthesia services. Can J Anaesth 2000;47:398-405.

26. Patton MQ. Qualitative Evaluation and Research Methods. Newbury Park: Sage Publications, 1990.

27. Corbin J, Strauss A. Basics of Qualitative Research. Thousand Oaks: Sage Publications, 2008.

28. Rubio DM, Berg-Weger M, Tebb SS, Lee ES, Rauch S. Objectifying content validity: Conducting a content validity study in social work research. Soc Work Res 2003;27:94-104.

29. Cassell E. The nature of suffering and the goals of medicine. N Eng J Med 1982;306:639-45.

30. Kahn DL, Steeves RH. Witnesses to suffering: Nursing knowledge, voice, and vision. Nurs Outlook 1994;42:260-4.

31. Wilson KG, Chochinov HM, McPherson CJ, et al. Suffering with advanced cancer. J Clin Oncol 2007;25:1691-7.

32. Schrijvers D, Meijnders P. Palliative care in adolescents. Cancer Treat Rev 2007;33:616-21. 




The Scientific World Journal
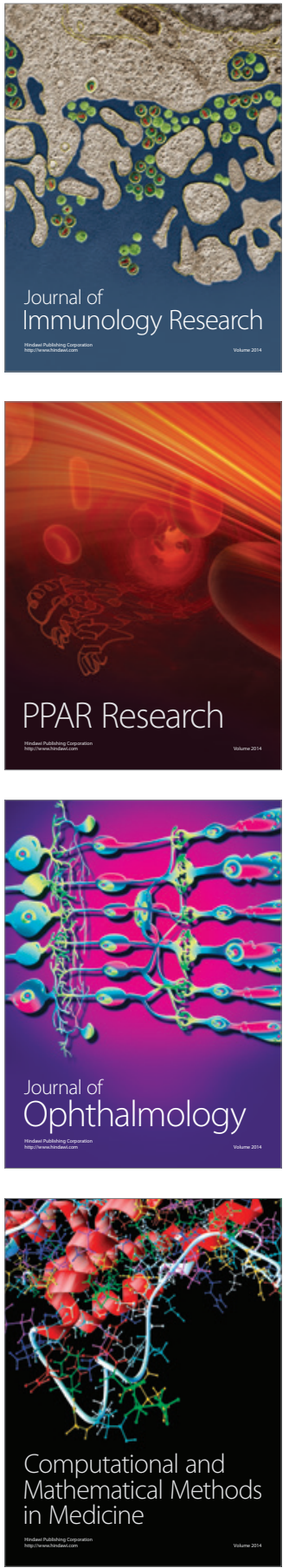

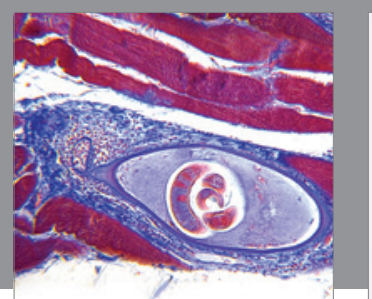

Gastroenterology Research and Practice

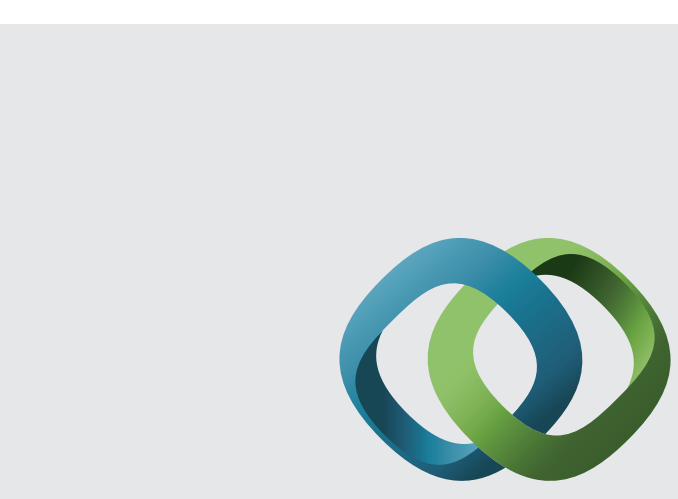

\section{Hindawi}

Submit your manuscripts at

http://www.hindawi.com
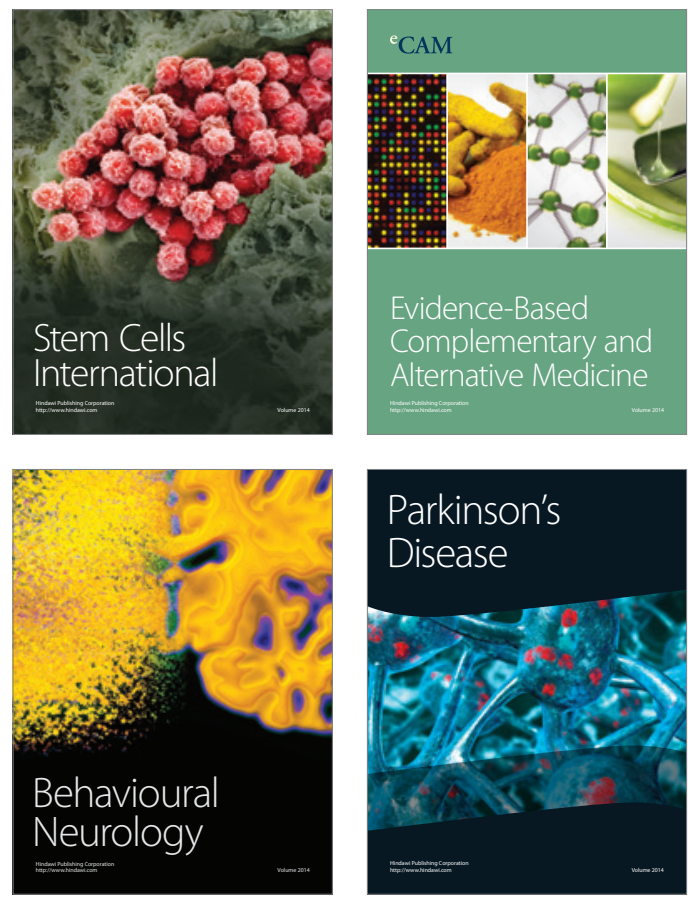
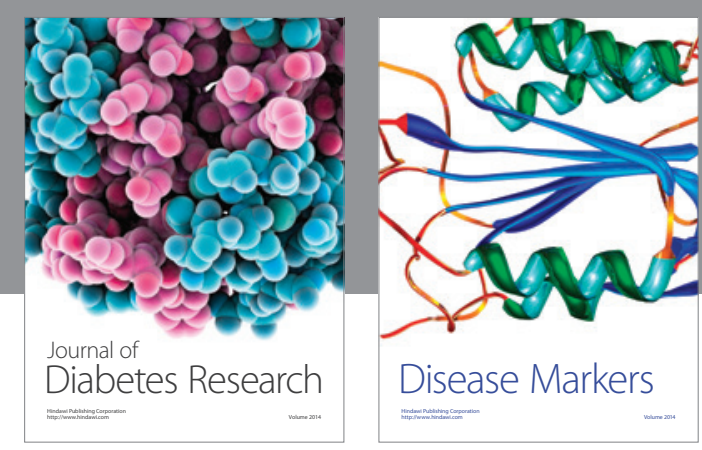

Disease Markers
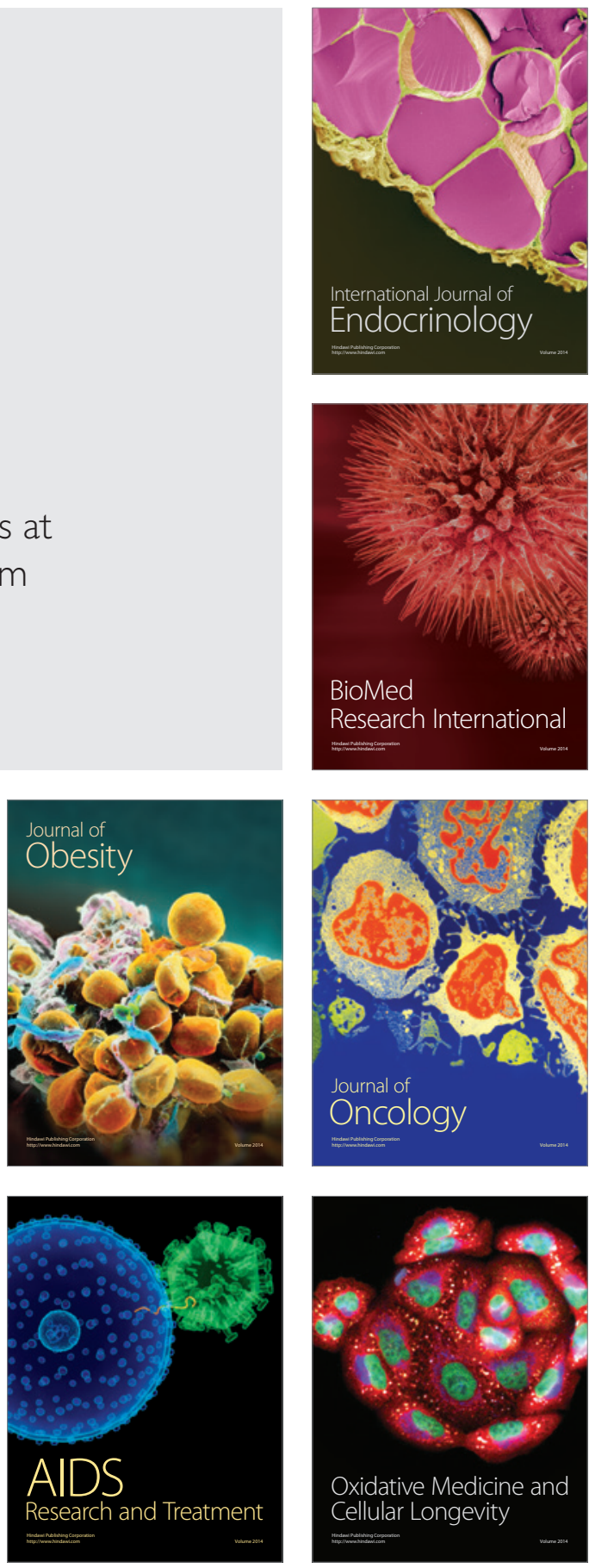